\title{
PSYCHE
}

Vol. 66

September, 1959

No. 3

\section{COMMUNICATION BY TANDEM RUNNING IN THE ANT GENUS CARDIOCONDYLA ${ }^{1}$}

\author{
By Edward O. Wilson \\ Biological Laboratories, Harvard University
}

During field work in Puerto Rico in June, 1960, the author had the opportunity to study a hitherto little known form of communication among worker ants. This behavior, which for convenience might be called tandem running, involves the movement outward from the nest of closely coupled tandem pairs, and it apparently functions as a substitute for trail-laying to recruit fellow workers to food sources. On Puerto Rico, tandem running was studied more fully in the species Cardiocondyla venustula Wheeler but was also observed in a second member of the genus, C. emeryi Forel.

\section{Natural History of $C$. venustula on Puerto Rico}

This species has been introduced by modern commerce into the West Indies and is probably native to some part of the Old World tropics. Wheeler (1908) in 1906 and the present author in 1960 found it abundant in the lowlands of Puerto Rico, especially in urban and other cultivated areas near the shore. The following generalizations are based on my 1960 observations, pertaining mostly to two colonies in urban Santurce.

As also noted by Wheeler, venustula colonies are small, in maturity containing probably no more than one or two hundred workers. Nests are built in open soil. Both Santurce nests were polydomous, with two or three entrances no farther than two meters apart. In each case most of the colony was concentrated in one of the subnests. Workers were often seen transporting brood and other adult workers between the subnests. In adult transport, the two ants face each other, and one grips the other by some part of the head (probably the mandibles) and swings it over its back; the transported worker as-

\footnotetext{
${ }^{1}$ Based on research supported by a grant from the National Science Foundation.
} 
sumes the "pupal" posture, with appendages tightly withdrawn. The nest entrances are circular or slit-shaped and large enough to accommodate only one or several ants at a time. Their appearance changes after each heavy rain, when excavation is renewed by the colony. Typically, the workers pile a circle of miscellaneous debris around the entrance holes. For example, the following particles were recorded around one chief entrance: dessicated fragments of Pheidole workers, small beetle elytron, unidentified piece of dry vegetable detritus, small tuft of cotton fibers. With each heavy rain the debris circle is washed away, but it is replaced within a few hours by the ants.

Foraging is most intense during the middle hours of the day, from late morning to middle afternoon. The workers seem to be most active in hot sunshine. As many as 23 were counted outside the larger of the two nests at peak activity. Workers hunt singly and range widely from the nest; a few were encountered as far as six meters away. Orientation is apparently visual; workers were frequently seen moving in nearly straight lines for considerable distances to and from the nests, and these could not be significantly disoriented by raking up soil in front of them. Venustula is principally, if not exclusively, a scavenger species. Following are records of food particles being brought to the nest by workers, made at random during a period of several hours: 8 pieces of unidentifiable material, probably insect in origin (see below); one fragment of insect unidentified to group; 4 body parts of another ant species, identified in 3 cases to Pheidole; 2 small beetles; one small spider; one cicadellid. In every case the insect material was either dried or, if fresh, crushed or mangled, obviously having been found in an inactive state by the venustula workers. No evidence of predation could be found. Workers were observed on many occasions to start away from the numerous small spiders, collembolans, cicadellids and other insects that swarmed in the nest vicinity. On the other hand, they readily accepted dead insects offered them. Insects too large to be carried back by a single worker were carved into manageable pieces by the foragers. The great majority of food particles brought to the nest ranged in size from slightly less than the volume of a venustula worker head to about three times this size. Workers also accepted sucrose solution readily.

\section{Tandem Running in C. venustula}

Workers of this species were never seen to lay or follow odor trails. Instead, a distinctive form of communication is employed during 
foraging that involves, in most cases, only two workers at a time. The leader moves outward from the nest, with a single follower close behind. The communication is as follows: the leader remains perfectly still until touched on the abdomen by the follower ant. Then it runs forward for a distance of approximately 3 to $10 \mathrm{~mm}$ (or one to several times its own body length), only to come to a complete halt again. The follower ant is in a highly excited state, apparently stimulated by a secretion released by the leader; other workers approaching the leader become similarly excited, even when the latter is completely immobile at the time. After each contact and subsequent "drive" of the leader forward, the follower may press immediately behind and drive it again. More commonly, it circles widely about in a hurried movement that usually lasts for several seconds and may take it as far as a centimeter from the path set by the leader. In short time, however, the circling brings the follower once again into contact with the leader. If it touches the leader on the head or from the side, the latter does not move. In such cases the follower invariably moves around to the rear of the leader, touches it on the abdomen and starts it forward again.

On three occasions, the author removed the follower worker with a pair of forceps and lightly touched the leader on the abdomen with a fine vegetable fiber or human hair in an attempt to drive it artificially. The attempts were only partly successful, perhaps because the stimulus was too crude. In each case the leader moved forward, stopped, was touched again, moved forward, stopped, was touched a third time, and continued running thereafter. The runs betwesn stimuli were somewhat longer than under natural conditions. The workers were successfully driven in this way only for distances of several centimeters before breaking away. In an attempt to induce following artificially, various body parts of workers were crushed on to the tips of strips of paper, which were then offered to workers around the nest entrance. Workers were both excited and mildly attracted, in contrast to a neutral or flight reaction to untreated strips, but they could not be induced to follow when the strips were drawn slowly over the ground.

In the great majority of cases, tandem running involved only two workers. Occasionally a third worker crowded in closely behind the leader worker but did not continue following for more than a few centimeters. Additional workers became excited by the leader only when they encountered it directly. There was no evidence of any kind of an odor trail. 
A total of 16 tandem trips away from the larger venustula nest were followed to completion. Two of these were abortive, breaking off less than I 5 centimeters from the nest. Seven led outward for distances of approximately one to two meters from the nest, in four cases to food baits set at this distance. The remaining seven led for three to five meters before breaking up or ending at a food source, a very considerable distance for so small an ant. All of the movements formed a nearly straight line, with only occasional, momentary doubling back. Eleven of the tandem runs ended without achieving any obvious goal. Five, however, ended at food sources, either dead insects occurring naturally or baits set by the author and both workers thereafter commenced feeding. Considering the greatly dispersed state of acceptable food, this seemed to be a highly significant proportion of "hits". Furthermore, almost all of the eleven fruitless runs were oriented in directions from which abundant food particles were being transported by other workers at the time.

The hypothesis was now considered, that tandem running is a means whereby newcomer ants are recruited to new food sources. This implies that the leader ant has visited the food source at least once and is now returning, bringing a sister worker in tow. The hypothesis could not be tested directly under field conditions, since workers were too small to mark with ink or paint and could not otherwise be traced when they re-entered the nest. However, the following indirect experimental evidence supports the hypothesis.

Baits were placed at varying distances from the nest and tandem pairs leaving the nest were followed during the next 30 or 60 minutes. In one experiment a small piece of moistened sugar was placed $10 \mathrm{~cm}$. from the main nest entrance. Two tandem pairs left in the observation period; one arrived at the sugar, the other proceeded to a dead homopteran lying naturally at a position about 4 meters away. In two additional experiments, small, freshly killed moths were placed at positions $15 \mathrm{~cm}$. and between one and two meters from the nest. Three tandem pairs arrived at these baits, while 5 moved in other directions. Thus in all three experiments five pairs arrived at targets and commenced feeding, while five went in other directions. Even if it is assumed that the five that missed were not heading for other, natural food sources, an unlikely proposition, the results are highly significant. Judging from the movements of individual workers approaching and passing baits in near-misses, the total angular sector through which individual (and tandem pairs) could move randomly outward and successfully hit the closest target was calculated as not 
greater than $30^{\circ}$ and probably less than $20^{\circ}$. This angle was less than $\mathrm{I}^{\circ}$ for the most remote targets. Thus the probability that pairs moving at random would hit one of the targets did not exceed O.I and was usually far less. The frequency of actual hits, 0.5, is highly significant. Furthermore, in each case of a hit, the pair at once broke apart and commenced feeding, indicating that recruitment was indeed the "goal" of their excursion.

Although tandem running is apparently devoted in part or entirely to the communication of food finds, it is employed only by a fraction of workers engaged in successful foraging. Less than 10\% of workers running from the nest to food masses were coupled in tandem pairs. This is in contrast to the high degree of participation shown by traillaying ant species such as Solenopsis saevissima (Fr. Smith), in which more than $90 \%$ of workers returning from rich food sources contribute material to the trail.

The nesting and foraging behavior of $C$. emeryi Forel appears to be very similar to that of venustula. On two occasions, at Santurce and Luquillo, Puerto Rico, pairs of emeryi workers were seen engaged in tandem running, apparently identical in form to that of venustula. This aspect of the behavior of emeryi has not been analyzed further.

\section{Discussion}

The first mention of tandem running in the literature is evidently that of Hingston (1928). This author gives the following description of foraging behavior in the Indian species Camponotus (Orthonotomyrmex) sericeus (Fabr.): "This ant nests on the ground and goes up trees in search of food. Its plan of communication is very simple, and, being so simple, is highly instructive. All that happens is that one ant leads another to the place where spoil has been found. One ant discovers spoil. It returns to the nest, finds a comrade and leads it to the required place. The two go off over the ground. The leader keeps in front; the led ant follows. Number two keeps in number one's footsteps, and repeatedly touches its tail. The leader moves particularly slowly in order not to lose connection with its follower. If number two happens to get out of touch, then the leader halts and waits until number two regains its place." In 1955, near Sydney, Australia, Mr. John Freeland showed me a pair of workers of an unidentified Camponotus engaged in tandem running quite similar to that in Cardiocondyla, although we did not guess the significance of the behavior at the time. Thus tandem running appears to be a wide- 
spread form of communication in ants. Perhaps further directed observation will show it to be more common than the meager existing data have indicated.

It is valuable to speculate, as Hingston (1928) and later Sudd ( I959) have done, that tandem running is a primitive communication form that can lead in evolution to trail laying. Hingston has described what appear to be excellent intermediate stages between tandem running and trail laying in the Indian species Camponotus ( $M y r-$ mosericus) paria Emery and $C$. (Tanaemyrmex) compressus (Fabr.). In paria the leader ant does not halt and wait to be touched, while the follower often drops behind 2 or 3 inches and seems to be orienting at least in part by a rudimentary odor trail. The behavior of compressus resembles that of paria except that as many as ten or twenty workers follow in a single file behind the leader.

Nevertheless, it will have to be remembered that in Cardiocondyla, at least, tandem running is a highly evolved behavioral pattern in its own right. It can be fairly said to include more complex individual behavior than trail-laying and trail-following. In particular, the simultaneous release of a chemical stimulus and the drive behavior of the leader ant are quite elaborate in comparison with other known forms of ant communication. Even so, it would be most interesting to know whether any of the other species of Cardiocondyla show behavior patterns intermediate between tandem leading and trail-laying, as is apparently the case in Camponotus.

\section{Literature Cited}

Hingston, R. W. G. 1928. Problems of instinct and intelligence. Arnold. SuDD, J. H. 1959. Interaction between ants on a scent trail. Nature, 183:1588. Wheeler, W. M. 1908. The ants of Puerto Rico and the Virgin Islands. Bull. Amer. Mus. Nat. Hist., 24 : 117-158. 

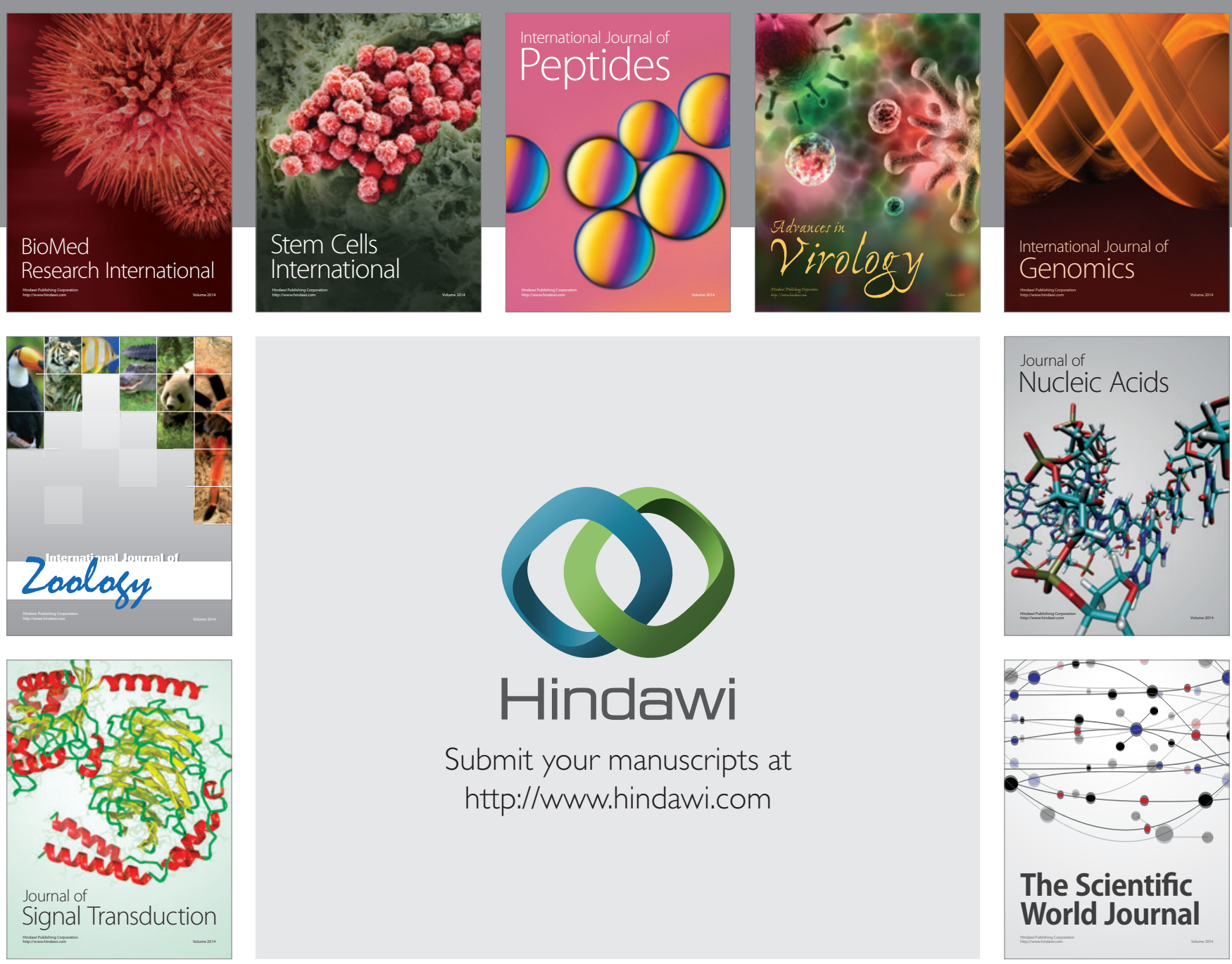

Submit your manuscripts at

http://www.hindawi.com
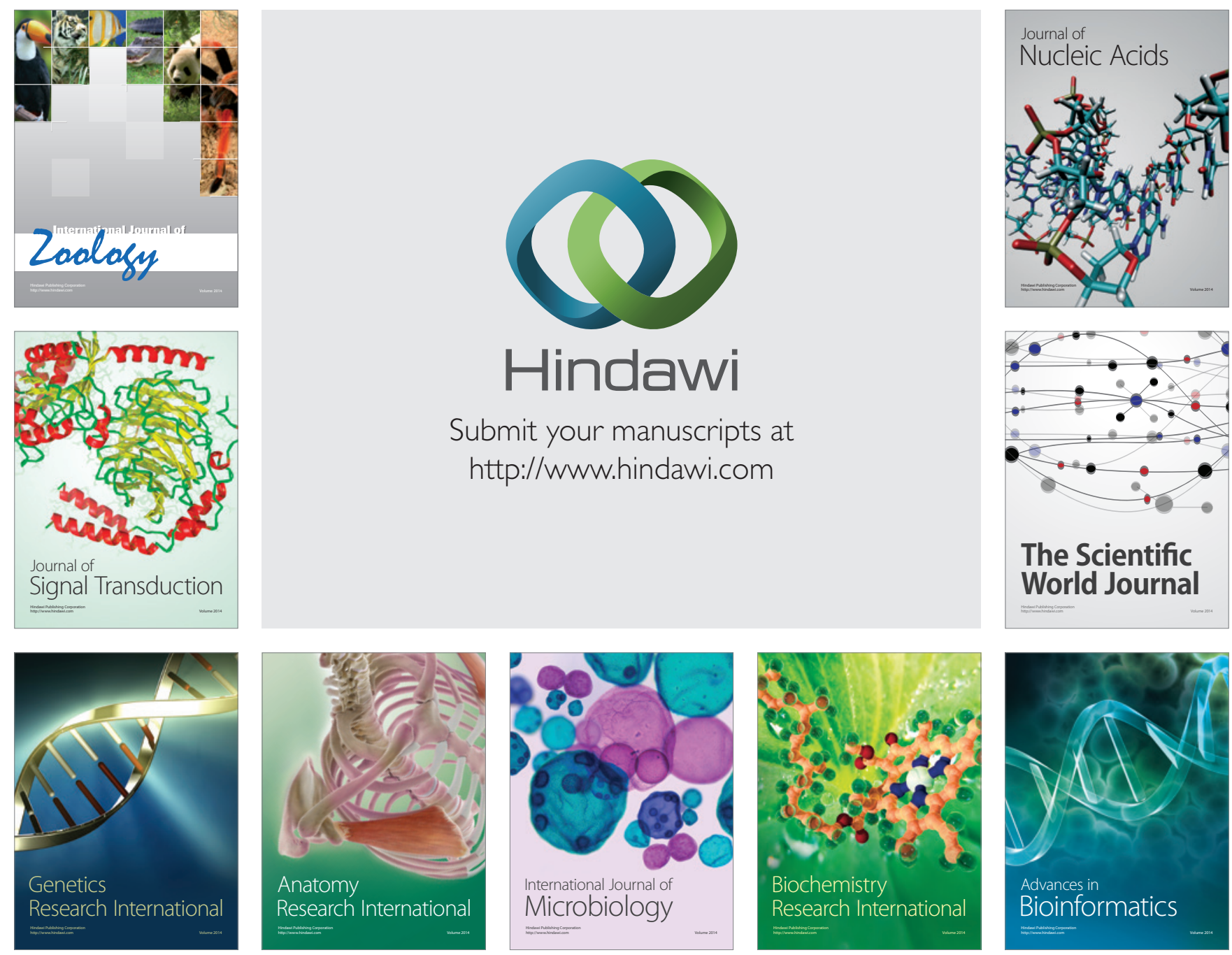

The Scientific World Journal
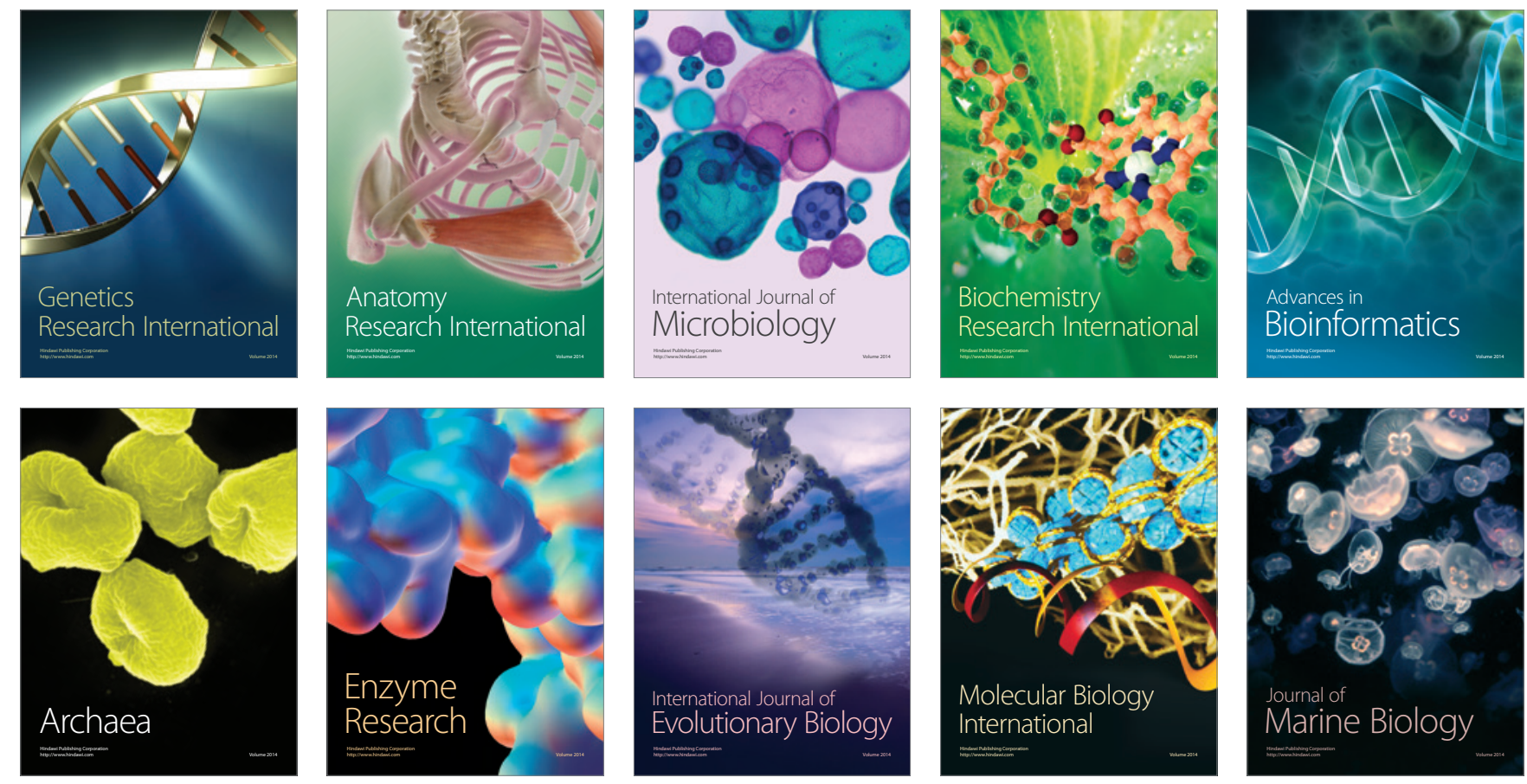